\title{
Individual, facility and policy level influences on national coverage estimates for intermittent preventive treatment of malaria in pregnancy in Tanzania
}

\author{
Tanya Marchant*1, Rose Nathan ${ }^{3}$, Caroline Jones², Hadji Mponda ${ }^{3}$, \\ Jane Bruce ${ }^{2}$, Yovitha Sedekia ${ }^{3}$, Joanna Schellenberg ${ }^{2}$, Hassan Mshinda ${ }^{3}$ and \\ Kara Hanson ${ }^{1}$
}

\begin{abstract}
Address: ${ }^{1}$ Department of Public Health and Policy, London School of Hygiene and Tropical Medicine, Keppel Street, London, UK, ${ }^{2}$ Department of Infectious and Tropical Diseases, London School of Hygiene and Tropical Medicine, Keppel Street, London, UK and ${ }^{3}$ Ifakara Health Institute, PO Box 78373, Mikocheni, Dar es Salaam, Tanzania

Email: Tanya Marchant* - tanya.marchant@lshtm.ac.uk; Rose Nathan - rosenathan2001@yahoo.co.uk;

Caroline Jones - caroline.jones@lshtm.ac.uk; Hadji Mponda - mpondah@yahoo.com; Jane Bruce - jane.bruce@lshtm.ac.uk;

Yovitha Sedekia - Sedekiay@yahoo.co.uk; Joanna Schellenberg - joanna.schellenberg@lshtm.ac.uk;

Hassan Mshinda - Hassan_Mshinda@yahoo.co.uk; Kara Hanson - Kara.Hanson@lshtm.ac.uk

* Corresponding author
\end{abstract}

Published: 18 December 2008

Malaria Journal 2008, 7:260 doi:10.1186/1475-2875-7-260

This article is available from: http://www.malariajournal.com/content/7///260

(C) 2008 Marchant et al; licensee BioMed Central Ltd.

This is an Open Access article distributed under the terms of the Creative Commons Attribution License (http://creativecommons.org/licenses/by/2.0), which permits unrestricted use, distribution, and reproduction in any medium, provided the original work is properly cited.
Received: 12 September 2008

Accepted: 18 December 2008

\begin{abstract}
Background: Delivery of two doses of intermittent preventive treatment of malaria during pregnancy (IPTP) is a key strategy to reduce the burden of malaria in pregnancy in sub-Saharan Africa. However, different settings have reported coverage levels well below the target $80 \%$. Antenatal implementation guidelines in Tanzania recommend IPTp first dose to be given at the second antenatal visit, and second dose at the third visit. This investigation measured coverage of IPTP at national level in Tanzania and examined the role of individual, facility, and policy level influences on achieved coverage.

Methods: Three national household and linked reproductive and child health $(\mathrm{RCH})$ facility surveys were conducted July-August 2005, 2006, and 2007 in 210 clusters sampled using two-stage cluster sampling from 21 randomly selected districts. Female residents who reported a livebirth in the previous year were asked questions about malaria prevention during that pregnancy and individual characteristics including education, pregnancy history, and marital status. The $\mathrm{RCH}$ facility serving each cluster was also surveyed, and information collected about drug stocks, health education delivery, and the timing of antenatal care delivery by clinic users.

Results: The national IPTp coverage had declined over the survey period being $71 \%$ for first dose in 2005 falling to $65 \%$ in $2007\left(\chi^{2} 2.9, p=0.05\right)$, and 38\% for second dose in 2005 but 30\% in $2007\left(\chi^{2} 4.4, p=0.01\right)$. There was no evidence of any individual factors being associated with second dose coverage beyond living in an urban area. Availability of sulphadoxine-pyrimethamine at RCH had decreased year on year from $85 \%$ of clinics in stock in 2005 to $60 \%$ in $2007\left(\chi^{2}\right.$ 20.6, $\mathrm{p}<0.00 \mathrm{I}$ ). This reduction was evident in rural but not urban clinics. If safety recommendations and national antenatal care guidelines for IPTp delivery were followed, in 2007 only $76 \%$ of pregnant women could have received IPTP first dose and only $46 \%$ could have received second dose.
\end{abstract}

Conclusion: There is scope to improve IPTp first and second dose coverage at national scale within existing systems by improving stock at $\mathrm{RCH}$, and by revising the existing guidelines to recommend delivery of IPTP after quickening, rather than at a pre-defined antenatal visit. 


\section{Background}

Over the last decade a number of reviews have firmly established the burden of malaria in pregnancy as a priority public health issue [1-4]. One intervention widely promoted to tackle this burden in malaria endemic areas in sub-Saharan Africa is intermittent preventive treatment for pregnant women (IPTp) [5,6].

With few exceptions, the implementation of IPTp has been integrated within the existing antenatal care structure as part of the WHO recommended focused antenatal care schedule [7]. The regime consists of the administration of two or three complete curative doses of an antimalarial medicine, the first after quickening - early in the second trimester - and subsequent doses at monthly intervals [8]. There is increasing awareness of the importance of administering at least two doses for a protective effect [9-12]. Currently, sulphadoxine-pyrimethamine (SP) is the recommended IPTp drug in several African countries although, in light of increasing malaria parasite resistance to $\mathrm{SP}$, alternative drugs are under investigation $[13,14]$.

It is estimated that $80 \%$ of women across sub-Saharan Africa access antenatal clinic at least once during pregnancy, and $74 \%$ at least twice [15]. SP is a relatively cheap drug, has been widely available, and is amenable to directly observed therapy requiring only a single dose for each treatment. In theory, therefore, IPTp coverage using SP should be high. However, as reported from many settings [16-21] second dose coverage has been disappointing, with one exception [22], and there is concern that the effectiveness of IPTp under programme conditions may be much reduced [23]. There is an urgent need to understand how the potential of this strategy can be realized.

Using national level linked household and facility data in Tanzania collected annually over the period 2005-2007, trends in IPTp coverage at a national scale are investigated, and the influence of individual, facility and policy level indicators on second dose IPTp coverage countrywide explored.

\section{Methods \\ Study setting}

The mainland of the United Republic of Tanzania, which excludes Zanzibar, has 133 districts across 21 regions and a population of over 33 million people. It is a country with high fertility and good access to antenatal care with over $95 \%$ of women having at least two antenatal visits [24]. The country is highly endemic for malaria and IPTp has been implemented as national policy for the last five years. The antenatal implementation schedule offers SP to all pregnant women attending antenatal clinics at their second visit between 20 and 24 weeks gestation for the first dose and at their third visit between 28 and 32 weeks for the second dose [25].

\section{Study design}

This investigation uses data collected as part of the Tanzanian National Voucher Scheme (TNVS) monitoring and evaluation conducted in July-August of 2005, 2006 and 2007, full details of which, including survey instruments used, are available elsewhere [26]. Three data sources are analysed: household surveys, reproductive and child health (RCH) facility surveys, and RCH user surveys.

(1) Household surveys were conducted in the same randomly selected 21 districts across mainland Tanzania in July/August each year with a two-stage cluster sample design. Ten clusters (wards) were selected with probability proportional to population size within each district. For each cluster a sub-village (kitongoji) was sampled with simple random sampling. Finally, 30 households were sampled from each cluster using a EPI sampling approach.

At each household, interviews were conducted in Kiswahili with the household head, with all women aged 15-49 and with all caregivers of children under five. An additional interview schedule was applied for women aged 15-49 who were currently pregnant, or who had had a live birth in the preceding year. These data are used to provide estimates on IPTp coverage and individual level influences.

(2) The RCH facility serving each cluster (described above) was selected for survey. At each facility, equipment and supplies were checked, staff and services provided recorded, health education sessions observed, and a review of routine antenatal record keeping was conducted. These data are used to explore the facility level characteristics influencing IPTp coverage estimates.

(3) At each RCH facility, up to a maximum of 7 women who accessed antenatal care on the day of survey were invited to be interviewed. The interview schedule included questions about timing of attendance to RCH throughout pregnancy, the timing of intervention delivery, and knowledge of specific aspects of malaria and reproductive health. These data are used to explore the policy level (specifically timing) characteristics influencing IPTp coverage estimates.

\section{Data analysis and definitions}

IPTp coverage was measured in the household survey. The definition applied was in line with that recommended by Roll Back Malaria [27]: "The proportion of all women surveyed who had a live birth in the last year who reported having received one (or at least two where stated) doses of IPTp during their last pregnancy." 
The residential status of households is defined at the Ward level from the 2002 Tanzanian National Census, grouped as urban and non-urban (rural/semi-urban).

The socio-economic status of households relative to each other is grouped by quintile, quintile 1 being most poor. This was derived from principal components analysis using a combination of variables including household head education level, housing conditions, asset ownership of household and whether the house was rented or not.

All estimates were adjusted for cluster sampling using svy commands in STATA 10 . The $\chi^{2}$ test was used to examine differences in IPTp coverage by explanatory variables within survey years, and to examine differences in IPTp coverage levels across survey years. A summary of respondents from the household and facility surveys included in this analysis is given in Table 1.

\section{Ethical approval}

The monitoring and evaluation protocol was approved by the ethical review committee at London School of Hygiene and Tropical Medicine, UK, and by the Institutional Review Board at Ifakara Health Institute, Tanzania. The purpose and potential risks arising from participation were explained to all sampled persons, and anonymity was assured. Each interviewee was asked to provide written consent.

\section{Results}

\section{Individual level characteristics}

Coverage of IPTP across time

Estimates for both first and second dose coverage of IPTp have declined over the period from $71 \%(836 / 1,171)$ in 2005 to $65 \%(791 / 1,214)$ in 2007 reporting first dose $\left(\chi^{2}\right.$ $2.9, \mathrm{p}=0.05)$ and $38 \%(443 / 1,171)$ in 2005 to $31 \%(370 /$ $1,214)$ in $2007\left(\chi^{2} 4.4, \mathrm{p} 0.01\right)$ reporting second dose (Table 2).

\section{Coverage of IPTp by individual characteristics}

Coverage was disaggregated for 2007 by the individual level characteristics of age, marital status, education level of the woman, household socio-economic status and residence (Table 2). Residence was highlighted as an important differential for IPTp first and second dose estimates, coverage being higher amongst women in urban than women in non-urban settings for first dose: $78 \%(74 / 95)$ compared to $64 \%(718 / 1119), \chi^{2} 4.8(\mathrm{p}=0.02)$ and for second dose: $44 \%$ (42/95) urban compared to $29 \%$ (329/ $1119)$ non-urban, $\chi^{2} 5.1(\mathrm{p}=0.02)$. There was evidence to suggest that women with education levels beyond completed primary, and more wealthy women, were more successful than other women in getting a first dose of IPTp but this was not true for second dose (Table 2).

\section{Reasons for not taking IPTP}

Women who reported attending an antenatal clinic when they were pregnant, who said they had not received the first dose of IPTp, were asked why they had not. Over 90\% reported that they had not been asked whether they wanted it, with a slight increase in the percent not asked by survey year: 2005: 92.0\% (307/334), 2006: $92.5 \%$ (355/384), and 2007: 96.2\% (406/422) ( $\left.\chi^{2} 2.8, \mathrm{p} 0.06\right)$. This finding does not appear to be linked to individual status for any of the survey years, with no difference in the percent not asked by socio-economic quintile $\left(\chi^{2} 2.0\right.$, p0.7), age $\left(\chi^{2} 4.0, \mathrm{p} 0.5\right)$, education $\left(\chi^{2} 2.2, \mathrm{p} 0.5\right)$ or by residence $\left(\chi^{2} 0.3, \mathrm{p} 0.8\right)$ of the woman in 2007.

\section{Facility level characteristics}

Stock of sulphadoxine/pyrimethamine at antenatal clinic

There was a decline in the number of $\mathrm{RCH}$ facilities with SP in stock on the day of the survey from $85 \%(161 / 190)$ in 2005 to $59 \%(78 / 192)$ in 2007 ( $\chi^{2} 20.6$, p < 0.001) across all levels of clinics (Table 3 ). This aggregate figure was dominated by declines in rural clinics from $84 \%$ $(105 / 125)$ in 2005 to $55 \%(73 / 133)$ in $2007\left(\chi^{2} 16.5, \mathrm{p}<\right.$ $0.001)$, but there was no difference in urban clinics, being $86 \%(19 / 22)$ in 2005 and 88\% (15/17) in $2007\left(\chi^{2} 1.1(\mathrm{p}\right.$ $=0.2)$.

Table I: Respondents to Household, RCH facility and RCH facility user surveys, Tanzanian National Voucher Scheme 2005-2007

\begin{tabular}{|c|c|c|c|}
\hline Year & 2005 & 2006 & 2007 \\
\hline \multicolumn{4}{|l|}{ TNVS Annual Survey Sample } \\
\hline N. Districts & 21 & 21 & 21 \\
\hline N. Clusters & 210 & 210 & 210 \\
\hline \multicolumn{4}{|l|}{ Household Survey } \\
\hline N. Households & 6199 & 6260 & 6198 \\
\hline N. Women with a live birth in previous 12 months & $|17|$ & 1229 & 1214 \\
\hline \multicolumn{4}{|l|}{$\mathrm{RCH}$ facility survey } \\
\hline N. Clinics & 190 & 188 & 192 \\
\hline N. Clinics providing outreach services & 108 & 100 & 122 \\
\hline $\mathrm{N} . \mathrm{RCH}$ facility user interviews & 848 & 862 & 914 \\
\hline
\end{tabular}


Table 2: Percent of women reporting that they received first or second dose of an anti-malarial drug as intermittent preventive treatment (IPTP) at RCH facilities in Tanzania, TNVS Household survey 2005-2007

\begin{tabular}{|c|c|c|c|c|}
\hline & $\begin{array}{l}\text { First dose } \\
\%(95 \% \mathrm{Cl})\end{array}$ & $\begin{array}{r}\chi^{2} \\
\text { (p-value) }\end{array}$ & $\begin{array}{l}\text { Second dose } \\
\%(95 \% \mathrm{Cl})\end{array}$ & $\begin{array}{r}\chi^{2} \\
\text { (p-value) }\end{array}$ \\
\hline \multicolumn{5}{|l|}{ For three survey years: } \\
\hline TNVS Household survey 2005 [N = II7I] & $71.4(67.8-74.7)$ & & $37.8(34.3-41.5)$ & \\
\hline TNVS Household survey 2006 [N = 1229] & $68.6(65.1-71.9)$ & & $35.2(31.7-38.9)$ & \\
\hline TNVS Household survey $2007[\mathrm{~N}=1214]$ & $65.2(61.3-68.9)$ & $2.9(0.05)$ & $30.5(27.2-34.2)$ & $4.4(0.01)$ \\
\hline \multicolumn{5}{|l|}{ For 2007 only: } \\
\hline \multicolumn{5}{|l|}{ Residence } \\
\hline Urban $[\mathrm{N}=95]$ & $77.8(66.1-86.4)$ & & $44.2(31.7-57.4)$ & \\
\hline Non-urban $[\mathrm{N}=1119]$ & $64.2(60.0-68.1)$ & $4.8(0.02)$ & $29.4(22.9-33.1)$ & $5.1(0.02)$ \\
\hline \multicolumn{5}{|l|}{ Education level } \\
\hline No education [N = 298] & $54.7(48.4-60.8)$ & & $26.8(21.2-33.3)$ & \\
\hline Incomplete primary $[\mathrm{N}=147]$ & $59.2(51.4-66.5)$ & & $29.9(23.4-37.4)$ & \\
\hline Complete primary $[\mathrm{N}=728]$ & $69.9(65.6-73.9)$ & & $31.6(27.6-35.9)$ & \\
\hline Secondary $+[N=4 I]$ & $80.5(65.1-90.1)$ & $10.2(<0.01)$ & $41.5(25.6-59.2)$ & $1.3(0.2)$ \\
\hline \multicolumn{5}{|l|}{ Marital Status } \\
\hline Married/co-habit [N = 1005] & $64.4(59.9-68.5)$ & & $30.5(27.0-34.3)$ & \\
\hline Previously married $[\mathrm{N}=101]$ & $72.3(62.4-80.4)$ & & $34.6(26.4-43.9)$ & \\
\hline Never married $[\mathrm{N}=108]$ & $66.7(56.2-75.7)$ & I.I (0.3) & $26.8(18.3-37.6)$ & $0.7(0.4)$ \\
\hline \multicolumn{5}{|l|}{ Age } \\
\hline$<20$ years $[\mathrm{N}=149]$ & $62.4(53.9-70.2)$ & & $29.5(22.6-37.5)$ & \\
\hline $20-24[\mathrm{~N}=316]$ & $65.2(58.9-70.9)$ & & $32.9(27.1-39.3)$ & \\
\hline $25-29[N=279]$ & $68.4(61.8-74.4)$ & & $32.3(26.3-38.9)$ & \\
\hline $30-34[N=238]$ & $64.3(57.0-70.9)$ & & $30.2(24.6-36.5)$ & \\
\hline $35-39[N=147]$ & $63.3(54.6-71.1)$ & & $30.5(20.3-43.2)$ & \\
\hline $40+[N=72]$ & $72.2(58.9-82.5)$ & $0.6(0.6)$ & $25.8(18.9-34.3)$ & $0.5(0.7)$ \\
\hline \multicolumn{5}{|l|}{ Socio-economic status } \\
\hline QI (Most poor) [N = 208] & $55.3(47.7-62.6)$ & & $26.9(20.9-33.8)$ & \\
\hline $\mathrm{Q} 2[\mathrm{~N}=291]$ & $60.5(53.6-66.9)$ & & $26.8(21.4-32.9)$ & \\
\hline Q3 [N = 244] & $67.2(60.6-73.2)$ & & $31.1(24.7-38.3)$ & \\
\hline $\mathrm{Q} 4[\mathrm{~N}=255]$ & $67.4(61.2-73.1)$ & & $32.5(26.8-38.8)$ & \\
\hline Q5 (Least poor) [N = 37I] & $76.7(69.5-82.6)$ & $5.9(<0.01)$ & $36.3(28.9-44.4)$ & $1.5(0.18)$ \\
\hline
\end{tabular}

This cross-sectional data reports on stock on the day of survey but not duration of stock-out. However, by linking the coverage estimates derived from $\mathrm{RCH}$ facility user interviews with the stock in the facility that day we are able to demonstrate the impact of stock-outs on access. In 2007, first dose IPTp coverage was only 41\% (49/121) amongst women accessing a facility experiencing a SP stock-out, compared to $89 \%(164 / 184)$ amongst women accessing a facility with SP stock that day $\left(\chi^{2} 54.3\right.$ (< $0.001)$.

\section{Visual aides for IPTP}

Not only was there a significant decline in SP stocks at $\mathrm{RCH}$ facilities but there was also a decline in the percent of facilities displaying posters explaining the purpose and benefits of IPTp from 70\% (134/190) in 2005 to 50\% $(96 / 191)$ in $2007\left(\chi^{2} 11.5, \mathrm{p}<0.001\right)$.

IPTp at outreach clinic

Around $60 \%$ of RCH clinics reported providing an outreach antenatal service to women in remote areas (Table 1). A decline was observed in the percent of facilities administering IPTp at outreach clinic from 63\% (68/108) in 2005 to $45 \%$ 55/122 in 2007 ( $\left.\chi^{2} 6.5, \mathrm{p} 0.001\right)$.

\section{Health education}

Health education sessions were observed in 54\% (111/ 190) of facilities in 2005, 67\% (126/188) in 2006 and $62 \%(118 / 191)$ in 2007. A check list was used to indicate which topics were mentioned during the observed session. Just under half of all sessions delivered malaria prevention messages, with no difference by year: $47 \%$ in $2005,43 \%$ in 2006 and 46\% in 2007 ( $\chi^{2} 0.2$, p0.8).

In 2006, as part of the RCH facility antenatal user interview, an exploration was made into pregnant women's understanding of malaria prevention options. 66\% (571/ 862 ) were unable to answer the question "How many times should you take the medicine to prevent malaria during pregnancy?" and a further 6\% (49/862) answered only one dose. 
Table 3: Stock of sulphadoxine pyrimethamine on the day of survey, TNVS RCH Facility Survey 2005-07

\begin{tabular}{|c|c|c|c|c|}
\hline & 2005 & 2006 & 2007 & $\chi^{2}$ (p-value) \\
\hline All & $\begin{array}{r}84.7(78.8-89.2) \\
{[N=190]}\end{array}$ & $\begin{array}{r}74.5(67.7-80.2) \\
{[N=188]}\end{array}$ & $\begin{array}{r}59.5(52.2-66.1) \\
{[N=192]}\end{array}$ & $20.6(<0.001)$ \\
\hline \multicolumn{5}{|c|}{ By level of facility } \\
\hline Dispensary & $\begin{array}{r}84.7(77.9-89.6) \\
{[N=150]}\end{array}$ & $\begin{array}{r}71.3(63.1-78.3) \\
{[N=136]}\end{array}$ & $\begin{array}{r}55.6(47.3-63.5) \\
{[N=144]}\end{array}$ & $19.3(<0.001)$ \\
\hline Health Centre & $\begin{array}{r}95.2(72.5-99.3) \\
{[N=21]}\end{array}$ & $\begin{array}{r}80.6(62.9-91.1) \\
{[N=31]}\end{array}$ & $\begin{array}{r}72.4(53.6-85.6) \\
{[N=29]}\end{array}$ & $3.2(0.04)$ \\
\hline Hospital & $\begin{array}{r}73.7(50.0-88.7) \\
{[N=19]}\end{array}$ & $\begin{array}{r}85.7(63.6-95.3) \\
{[N=21]}\end{array}$ & $\begin{array}{r}68.4(44.9-85.2) \\
{[N=19]}\end{array}$ & $0.9(0.3)$ \\
\hline$\chi^{2}(p \text {-value })^{2}$ & $1.7(0.1)$ & $1.3(0.2)$ & $1.7(0.1)$ & \\
\hline \multicolumn{5}{|l|}{ By residence } \\
\hline Rural & $\begin{array}{r}84.0(76.4-89.5) \\
{[N=125]}\end{array}$ & $\begin{array}{r}72.3(63.9-79.4) \\
{[N=130]}\end{array}$ & $\begin{array}{r}54.9(46.3-63.2) \\
{[N=133]}\end{array}$ & $16.5(<0.00 \mid)$ \\
\hline S-Urban & $\begin{array}{r}86.0(72.1-93.6) \\
{[N=43]}\end{array}$ & $\begin{array}{r}70.7(55.0-82.6) \\
{[N=41]}\end{array}$ & $\begin{array}{r}61.9(46.4-75.3) \\
{[N=42]}\end{array}$ & $3.5(0.03)$ \\
\hline Urban & $\begin{array}{r}86.4(64.9-95.6) \\
{[N=22]}\end{array}$ & $\begin{array}{r}100 \\
{[N=17]}\end{array}$ & $\begin{array}{r}88.2(62.9-97.1) \\
{[N=17]}\end{array}$ & $1.2(0.2)$ \\
\hline$\chi^{2}(\mathrm{p} \text {-value })^{2}$ & $0.07(0.9)$ & $3.3(0.03)$ & $3.5(0.03)$ & \\
\hline
\end{tabular}

$\chi^{2}$ (p-value)' for difference between survey years

$\chi^{2}(\mathrm{p} \text {-value })^{2}$ for difference within survey years

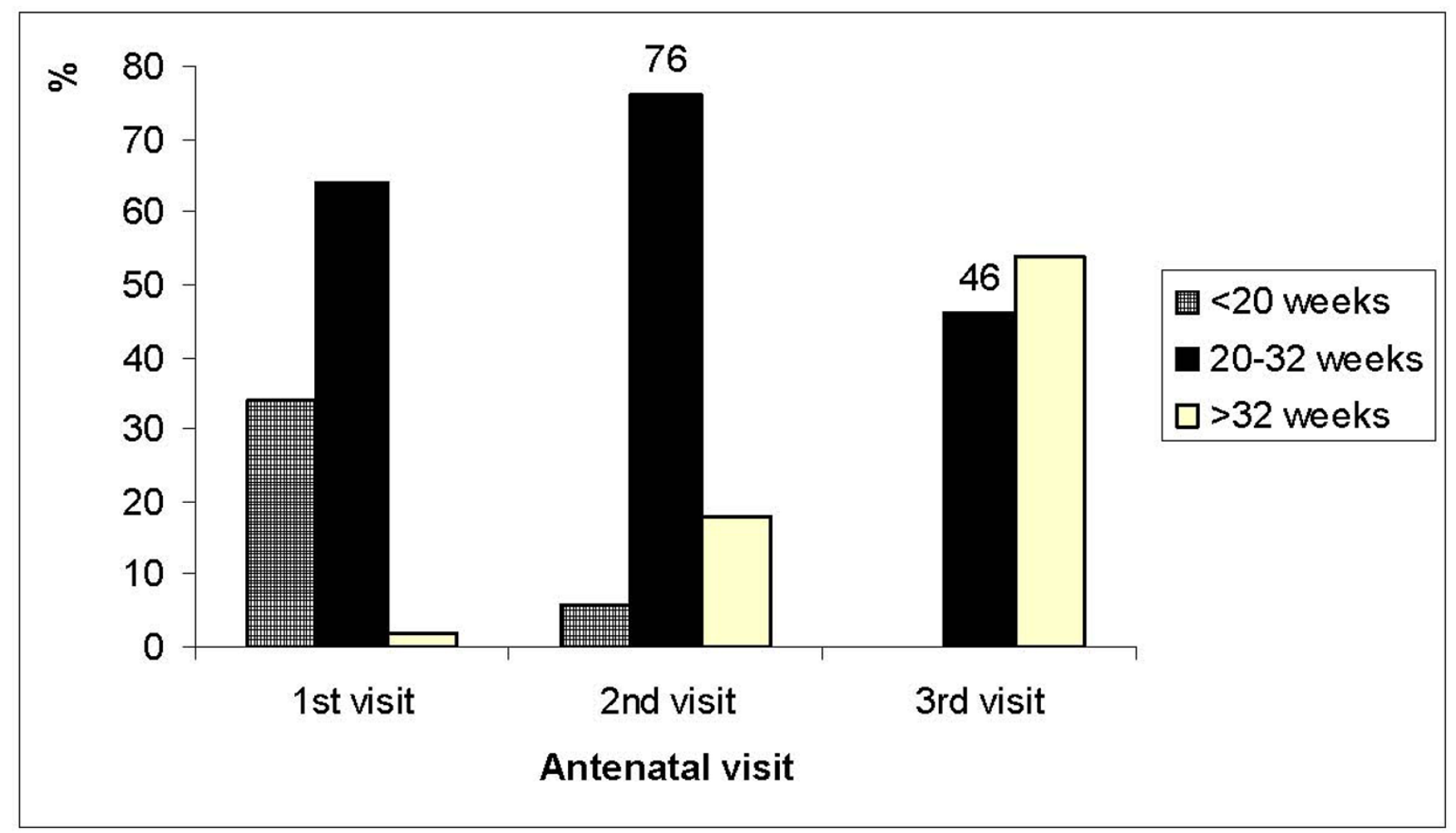

\section{Figure I}

Distribution of antenatal attendance $<20$ weeks (too early IPTP), 20-32 weeks (recommended IPTp) and > 32 weeks (too late IPTP) gestation at first, second and third antenatal visits to RCH facility, TNVS RCH facility survey, 2007. 


\section{Policy level}

IPT schedule for delivery

Pregnant women in Tanzania are recommended to first attend antenatal clinic by 16 weeks gestation, their second visit to take place around 20 weeks, and third around 28 weeks. In this population however (and typical of subSaharan Africa) the median gestation at first visit was 20 weeks and the median gestation at second visit was 26 weeks. In reality, therefore, women attend clinic later than recommended antenatal policy and this is found to disrupt the antenatal schedule for delivery of IPTp which recommends delivery of IPTp first dose at the second antenatal visit.

In Figure 1, the gestation of women at first, second, and third antenatal visit is grouped according to implication for IPTp delivery (<20 weeks: too early; 20-32 weeks: recommended; > 32 weeks: too late). At the first visit, $64 \%$ of pregnant women were within the recommended gestation to receive IPTp yet current policy recommends IPTp be given at second visit, and potentially these women were missed. At the second visit, $76 \%$ of pregnant women were within the recommended gestation to receive IPTp in accordance with policy. At the third visit, only $46 \%$ of pregnant women were within the recommended gestation to receive IPTp second dose in accordance with antenatal policy. These figures are not dissimilar to the coverage estimates of $65 \%$ and $31 \%$ for first and second dose (Table 2).

\section{Discussion}

Across mainland Tanzania in 2007, 65\% of women who had a pregnancy in the previous year reported receiving first dose of IPTp and 30\% second dose. This national level analysis of individual, facility and policy influences on coverage has revealed that throughout the period 2005-2007 delivery of second dose was negatively influenced by facility level factors, and probably policy related factors in Tanzania, but not by the individual characteristics of women beyond living in an urban area.

A lack of association between uptake of two doses of IPTp and individual factors in Tanzania has been reported previously, right from the beginning of IPTp implementation. The Demographic and Health Survey conducted in 2004 - soon after nationwide IPTp implementation found no individual level association with IPTp second dose, nor did a small-scale exploration during the same time-period [24,28]. Our finding of $65 \%$ first dose and $30 \%$ second dose coverage shows some improvement on the 2005 Demographic and Health Survey estimates, 53\% and $22 \%$ respectively, but remains far from the target of $80 \%$.
This analysis uses responses following the lead question "When you went to the clinic were you given the medicine to prevent malaria?" Restricting the data to only those women who could state the type of drug administered considerably restricts the number of valid responses as women frequently cannot state the drug used. However, the only drug administered as IPTp during the study period was SP. Observations from the facility survey suggest that stock outs of SP had a dramatic effect on coverage of the intervention. Previously the delivery of IPTp benefited from using the same drug as the first-line anti-malarial treatment drug, SP, and needed no separate delivery system. It would appear that since the change over to coartemether lumifantrine in 2006, the mechanisms for maintaining stocks of SP for IPTp require urgent attention, particularly in non-urban settings. It is worth mentioning here that facility user data is prone to responder bias as participants tend to give more positive responses than in population level household surveys and therefore levels of coverage observed may not be comparable between the two sources. However, the finding that coverage was at least $100 \%$ higher for women who attended a clinic with SP in stock than women who attended a clinic with no SP is likely a true reflection of the problem.

Less than half of health education sessions observed delivered malaria prevention messages. Such observations are sometimes associated with a Hawthorne effect - that workers observed for a short period of time tend to improve performance - and so the reality may be lower. The finding is surprising in Tanzania where there is clear commitment to reducing the burden of malaria and a number of initiatives have been designed to raise the profile of malaria nationally. It is worthwhile to investigate why these training and support initiatives are not translating into measurable delivery of clear malaria prevention messages to clinic users.

The delivery of IPTp at outreach clinics was reported to have declined during the period of the surveys. Again, this finding is contrary to the strong national commitment to control malaria. It is possible that this has arisen because of drug shortages - with rationing of SP for clinic based services taking place. Certainly barriers to delivery of IPTp at outreach where the most remote and vulnerable women are targeted should be addressed.

The schedule for delivery of IPTp has been scrutinized over the last year in a number of settings [9,29-31]. The Tanzanian antenatal policy of giving IPTp first dose at the second antenatal visit and second dose at the third antenatal visit was developed in part for its simplicity, and to minimize the burden placed on health staff from the increasing number of interventions being channelled through antenatal clinics. However, for high coverage to 
be realized, this policy demands simultaneous behaviour change from the pregnant woman population - to first attend clinic earlier than the current median of 20 weeks gestation - and from the facility worker - to implement the schedule. A previous small scale study in Tanzania found that facility workers do aim to stay within the recommendation for IPTp delivery, and reported missed opportunities for protecting pregnant women with two doses [16]. The Tanzanian antenatal guideline is critically different from the current WHO recommendation to distribute SP to all pregnant women at the first visit after quickening [8]. This is also designed to be an easily operationalized policy which stays within safety limits of SP in pregnancy, and importantly is not dependent on individual timing preferences for first attendance to antenatal clinic. It may be that the Tanzanian IPTp antenatal schedule should be revised accordingly while there is no evidence of behaviour change for earlier first attendance to clinic.

Results from investigations on a smaller-scale in subSaharan Africa have indicated a combination of lack of awareness, health worker behaviour, stock-outs and policy as possible explanations for low recorded coverage of IPTp [16,18-20,32]. Our national level analysis indicates that, in Tanzania, successful delivery of at least two doses of IPTp relies on facility and policy level factors that could potentially be resolved. Following a trial of IPTp implementation in the community compared to routine clinics, Mbonye and others [33] found that the community approach resulted in higher - and earlier - two-dose coverage than the routine approach. However, they caution that it would be important to support access to routine care where all other access to antenatal services was focussed. In Zambia, where high coverage of IPTp second dose has been achieved and sustained within existing systems, an analysis of enabling factors highlights co-ordinated support to the routine clinic system and training to antenatal care workers as key enabling factors [22].

\section{Conclusion}

Acting upon the observed rural stock outs and unintentionally restrictive antenatal guidelines in Tanzania is the most direct and sustainable option for optimising delivery of IPTp with SP. The challenge posed to IPTp with SP by increasing drug resistance of the Plasmodium falciparum parasite is beyond the operational control of the health system. Should a new drug for IPTp be recommended, the obstacles to high coverage will undoubtedly persist. It is essential that lessons are learned on how to maximize the existing regime in order to avoid any backward step on the road to $80 \%$ access.

\section{Competing interests}

The authors declare that they have no competing interests.

\section{Authors' contributions}

TM and KH participated in design and implementation of the study, data analysis and interpretation. RN and HM participated in design and implementation. CJ contributed to design of the study and interpretation of the findings. JB participated in design and data analysis. YS contributed to implementation of the study and interpretation of data. HS and JS supported activities at each stage. TM wrote the first draft of this manuscript. All authors contributed to, and approved, the manuscript for publication.

\section{Acknowledgements}

We are grateful to the National Malaria Control Programme and the TNVS implementing partners. Karen Kramer and Christian Lengeler made important contributions to the overall design of the surveys. Thanks are especially due to Dr Alex Mwita, Dr Renata Mandike and Nick Brown for their continued support to the evaluation process. This paper is published with the permission of the Director of the Tanzanian National Institute for Medical Research. No conflict of interest is declared. This work was supported by the Tanzania Ministry of Health and Social Welfare through a grant from the Global Fund to flight AIDS, TB and Malaria, the Gates Malaria Partnership funded by the Bill and Melinda Gates Foundation, and Population Services International, supported by the UK Department for International Development and the Royal Netherlands Embassy in 2005/06, and by the United States President's Malaria Initiative in 2007.

\section{References}

I. Desai M, ter Kuile FO, Nosten F, McGready R, Asamoa K, Brabin B, Newman RD: Epidemiology and burden of malaria in pregnancy. Lancet Infect Dis 2007, 7:93-104.

2. Guyatt HL, Snow RW: The epidemiology and burden of Plasmodium falciparum-related anemia among pregnant women in sub-Saharan Africa. Am J Trop Med Hyg 200I, 64(I-2 Suppl):36-44.

3. Menendez C, D'Alessandro U, ter Kuile FO: Reducing the burden of malaria in pregnancy by preventive strategies. Lancet Infect Dis 2007, 7:126-135.

4. Steketee RW, Nahlen BL, Parise ME, Menendez C: The burden of malaria in pregnancy in malaria-endemic areas. Am J Trop Med Hyg 200I, 64(I-2 Suppl):28-35.

5. United Nations: Millenium Development Goals. [http:// www.undp.org/mdg/].

6. World Health Organisation: Global strategy plan 2005-2015. [http://www.rollbackmalaria.org/forumV/docs/gsp en.pdf].

7. JHPIEGO: Focus on MIP: Overview of Focused Antenatal Care. [http://www.jhpiego.org/media/focuson/ mip ovwmip200603.htm].

8. WHO: Malaria in Pregnancy. Guidelines for measuring key monitoring and evaluation indicators. [http://www.who.int/ malaria/malariainpregnancy.html].

9. Gill CJ, Macleod WB, Mwanakasale V, Chalwe V, Mwananyanda L, Champo D, Mukwamataba D, Chilengi R, Thea DM, Hamer DH: Inferiority of single-dose sulfadoxine-pyrimethamine intermittent preventive therapy for malaria during pregnancy among HIV-positive Zambian women. J Infect Dis 2007, 196:1577-1584.

10. Sirima SB, Cotte AH, Konate A, Moran AC, Asamoa K, Bougouma EC, Diarra A, Ouedraogo A, Parise ME, Newman RD: Malaria prevention during pregnancy: assessing the disease burden one year after implementing a program of intermittent preventive treatment in Koupela District, Burkina Faso. Am J Trop Med Hyg 2006, 75:205-2II.

II. van Eijk AM, Ayisi JG, ter Kuile FO, Otieno JA, Misore AO, Odondi JO, Rosen DH, Kager PA, Steketee RW, Nahlen BL: Effectiveness of intermittent preventive treatment with sulphadoxinepyrimethamine for control of malaria in pregnancy in west- 
ern Kenya: a hospital-based study. Trop Med Int Health 2004, 9:35I-360

12. Verhoeff FH, Brabin BJ, Chimsuku L, Kazembe P, Broadhead RL: Malaria in pregnancy and its consequences for the infant in rural Malawi. Ann Trop Med Parasitol I999, 93(Suppl I):S25-33.

13. Vallely A, Vallely L, Changalucha J, Greenwood B, Chandramohan D: Intermittent preventive treatment for malaria in pregnancy in Africa: what's new, what's needed? Malar J 2007, 6:16.

14. WHO: Technical Expert Group meeting on intermittent preventive treatment in pregnancy (IPTp). [http://www.who.int/ malaria/docs/IPTp/TechnicalExpertMtgIPTpReport.pdf].

15. ORC Macro: Measure DHS STAT compiler. [http://www.meas uredhs.com].

16. Anders K, Marchant T, Chambo P, Mapunda P, Reyburn H: Timing of intermittent preventive treatment for malaria during pregnancy and the implications of current policy on early uptake in north-east Tanzania. Malar J 2008, 7:79.

17. Crawley J, Hill J, Yartey J, Robalo M, Serufilira A, Ba-Nguz A, Roman E, Palmer A, Asamoa K, Steketee R: From evidence to action? Challenges to policy change and programme delivery for malaria in pregnancy. Lancet Infect Dis 2007, 7:145-155.

18. Gikandi PW, Noor AM, Gitonga CW, Ajanga AA, Snow RW: Access and barriers to measures targeted to prevent malaria in pregnancy in rural Kenya. Trop Med Int Health 2008, 13:208-2 17.

19. Ouma PO, Van Eijk AM, Hamel MJ, Sikuku E, Odhiambo F, Munguti K, Ayisi JG, Kager PA, Slutsker L: The effect of health care worker training on the use of intermittent preventive treatment for malaria in pregnancy in rural western Kenya. Trop Med Int Health 2007, I 2:953-96 I.

20. Tarimo SD: Appraisal on the prevalence of malaria and anaemia in pregnancy and factors influencing uptake of intermittent preventive therapy with sulfadoxine-pyrimethamine in Kibaha district, Tanzania. East Afr J Public Health 2007, 4:80-83.

21. Kiwuwa MS, Mufubenga P: Use of antenatal care, maternity services, intermittent presumptive treatment and insecticide treated bed nets by pregnant women in Luwero district, Uganda. Malar J 2008, 7:44.

22. Steketee RW, Sipilanyambe N, Chimumbwa J, Banda JJ, Mohamed A, Miller J, Basu S, Miti SK, Campbell CC: National malaria contro and scaling up for impact: the Zambia experience through 2006. Am J Trop Med Hyg 2008, 79:45-52.

23. Briand V, Cottrell G, Massougbodji A, Cot M: Intermittent preventive treatment for the prevention of malaria during pregnancy in high transmission areas. Malar J 2007, 6:160.

24. DHS: Tanzania Demographic and Health Survey 2004-05. [http://www.nbs.go.tz/DHS/index.htm].

25. Ministry of Health and Social Welfare T: National Guidelines for Malaria Diagnosis and Treatment. United Republic of Tanzania Ministry of Health NMCP. Dar es Salaam; 2006.

26. Hanson K, Nathan R, Marchant T, Mponda H, Jones C, Bruce J, Stephen G, Mulligan J, Mshinda H, Schellenberg JA: Vouchers for scaling up insecticide-treated nets in Tanzania: methods for monitoring and evaluation of a national health system intervention. BMC Public Health 2008, 8:205.

27. Roll Back Malaria: Guidelines for core population coverage indicators for Roll Back Malaria. To be obtained from household surveys. Calverton, Maryland. 2006.

28. Nganda RY, Drakeley C, Reyburn H, Marchant T: Knowledge of malaria influences the use of insecticide treated nets but not intermittent presumptive treatment by pregnant women in Tanzania. Malar J 2004, 3:42.

29. Hamer DH, Mwanakasale V, Macleod WB, Chalwe V, Mukwamataba D, Champo D, Mwananyanda L, Chilengi R, Mubikayi L, Mulele CK: Two-dose versus monthly intermittent preventive treatment of malaria with sulfadoxine-pyrimethamine in HIV seropositive pregnant Zambian women. J Infect Dis 2007, 196:1585-1594.

30. Mbonye AK, Schultz Hansen K, Bygbjerg IC, Magnussen P: Effect of a community-based delivery of intermittent preventive treatment of malaria in pregnancy on treatment seeking for malaria at health units in Uganda. Public Health 2008, 1 22:516-525.

31. Peters PJ, Thigpen MC, Parise ME, Newman RD: Safety and toxicity of sulfadoxine/pyrimethamine: implications for malaria prevention in pregnancy using intermittent preventive treatment. Drug Saf 2007, 30:48I-50I.
32. Mubyazi G, Bloch P, Kamugisha M, Kitua A, ljumba J: Intermittent preventive treatment of malaria during pregnancy: a qualitative study of knowledge, attitudes and practices of district health managers, antenatal care staff and pregnant women in Korogwe District, North-Eastern Tanzania. Malar J 2005, 4:31.

33. Mbonye AK, Bygbjerg I, Magnussen P: Intermittent preventive treatment of malaria in pregnancy: a community-based delivery system and its effect on parasitemia, anemia and low birth weight in Uganda. Int J Infect Dis 2008, I 2:22-29.
Publish with Bio Med Central and every scientist can read your work free of charge

"BioMed Central will be the most significant development for disseminating the results of biomedical research in our lifetime. "

Sir Paul Nurse, Cancer Research UK

Your research papers will be:

- available free of charge to the entire biomedical community

- peer reviewed and published immediately upon acceptance

- cited in PubMed and archived on PubMed Central

- yours - you keep the copyright 